\title{
APLICACIONES DE TÉCNICAS ESPECTROSCÓPICAS PARA EL ANÁLISIS DE SUELOS
}

Fecha de recepción: 2 de mayo de 2016 • Fecha de Evaluación: 25 de junio de 2016 • Fecha de aceptación: 11 de julio de 2016 - Disponible en línea: 25 de julio de 2016

APPLICATIONS OF SPECTROSCOPY TECHNIQUES FOR SOIL ANALYSIS

Wilson Rodríguez P1․, Paola A. García R²., Alberto Fajardo $\mathrm{O}^{3}$.

\section{RESUMEN}

Existe una gran diversidad de técnicas analíticas en el estudio de suelos, siendo las técnicas espectroscópicas las que mayor auge han tenido recientemente ante la necesidad de buscar metodologías que permitan estudiar adecuadamente grandes extensiones de tierra y que sean amigables con el ambiente. Por esto es necesario revisar dentro de las actuales técnicas espectroscópicas usadas en análisis de suelos cual sería la técnica más adecuada para incorporar en los servicios de extensión en suelos en Colombia bajo los lineamientos dados anteriormente. La espectroscopía infrarrojo es la técnica más pertinente para incorporar en los análisis de fertilidad de suelos en Colombia considerando su versatilidad, bajo costo y reproducibilidad. Asociando los datos de IR con el uso de análisis quimiométrico se pueden lograr estimaciones de parámetros edáficos con alto grado de certeza, con lo cual se genera una nueva estrategia de trabajo en laboratorio ambientalmente más amigable.

Palabras Claves: Ultravioleta, infrarrojo, rayos X, resonancia magnética nuclear, espectrometría de masas.

1 Estudiante de Doctorado Ciencias Naturales y Desarrollo Sustentable. Universidad de la Amazonia. Investigador Grupo de investigación de Biotecnología \& control de Calidad de Alimentos. Magister en Ciencias Químicas - Universidad Nacional. Docente Universidad de la Amazonia. Correo de Contacto: gbiotecnologiaccm@gmail.com

2 Estudiante de Doctorado Agroindustria y Desarrollo Agrícola Sostenible. Universidad Surcolombiana. Magister en Agroforesteria - Universidad de la Amazonia. Investigador Grupo de investigación de Biotecnología \& Control de Calidad de Alimentos. Grupo de investigación Agroindustria USCO. Docente Universidad de la Amazonia.

3 Docente de la Universidad de la Amazonia. Doctor en Ciencias - Universidad Nacional de Colombia. Magister en Geología e Geoquímica - Universidade Federal Do Paraá. 


\section{ABSTRACT}

There is a wide variety of analytical techniques in the study of soils, with spectroscopic techniques which have recently been more boom to the need to seek methodologies to properly study large tracts of land and are environmentally friendly. Therefore it is necessary to review within the current spectroscopic techniques used in soil analysis which would be the most appropriate technique to incorporate extension services in soils in Colombia under the guidelines given above. Infrared spectroscopy is the most appropriate to incorporate into the analysis of soil fertility in Colombia considering its versatility, low cost and reproducibility technique. Associating IR data using chemometric analysis can be achieved estimates of soil parameters with a high degree of certainty with which a new work strategy more environmentally friendly lab is generated.

Keywords: Utraviolet Infrared, X-ray, magnetic resonance, mass spectrometry.

\section{INTRODUCCIÓN}

El análisis de suelos tradicional caracteriza física y químicamente el suelo, cuya información generada permite posteriormente incrementar la productividad, y buscar las prácticas agrícolas adecuadas, para lograr alta calidad del suelo (Qui et al, 2009), éstos análisis han permitido potenciar prácticas agrícolas tales como riego, fertilización, y encalado de suelos bajo bosque inicialmente y convertidos en suelos de uso agrícola, esto implica buen manejo, y conocer con que insumos se puede trabajar para determinado tipo de suelo (Castilla et al, 2010). El análisis físico y químico de suelos convencional, en Colombia, está basado en técnicas volumétricas, gravimétricas, de espectrofotometría visible, difracción de rayos $X$, espectroscopía de absorción atómica (EAA), turbidimetría, potenciometría y conductivimetría (Zamudio et al, 2006), que aportan valores in situ e in vitro de cada parámetro de utilidad agrícola (Jaramillo, 2004), lo cual ayuda a conocer la calidad del suelo (Morugán et al, 2013). Algunos procedimientos de análisis de suelos aparecen dentro de las normas que emite el Instituto Colombiano de Normas Técnicas y Certificación (ICONTEC) tales como NTC 5889 relacionada con determinación de nitrógeno total y NTC 5403 que trata de determinación del Carbono Orgánico (García y Ballesteros, 2005). No obstante estos procedimientos de laboratorio (química húmeda) son consumidores de tiempo, costosos y generadores de grandes cantidades de residuos de sustancias químicas que contaminan el ambiente.

De otro lado, ante la creciente demanda de bases de datos (regionales, continentales o mundiales), para monitorear el estado del suelo, es necesario buscar herramientas de bajo costo. La espectroscopía del suelo ha mostrado ser una herramienta rápida, de bajo costo, ambientalmente amigable, no destructiva y reproducible (Nocita et al, 2015), constituyéndose en un campo en continuo crecimiento. Algunos trabajos han presentado la utilidad de la espectroscopía en análisis de suelos. Roach y Reddy (2004), revisaron técnicas espectroscópicas como resonancia magnética nuclear (RMN), infrarrojo (IR), 
Raman, de haz electrónico y rayos $\mathrm{X}$, entre otros, en la caracterización de suelos contaminados con metales. Chabrillat et al, (2013), evidenciaron la relación entre las diferentes regiones del IR y los diferentes componentes del suelo. De otro lado, Armenta y Guardia (2014) reportaron ventajas y desventajas de la espectroscopía vibracional (IR y Raman), en análisis de suelos y sedimentos. Nocita et al, (2015), evidenciaron la necesidad de recopilar los múltiples análisis de suelos de diferentes latitudes para generar bases de datos que se puedan relacionar con las actuales librerías espectrales y tratar de corregir las fallas que presentan el análisis espectroscópico del suelo a escala local.

Es necesario revisar las actuales técnicas espectroscópicas usadas en los análisis de suelos para evaluar su versatilidad en la estimación de parámetros de física y química del suelo con alto grado de confiabilidad y así, poder sugerir cuál de las actuales técnicas espectroscópicas sería la más conveniente de incorporar en los servicios de extensión de análisis de suelos en Colombia. Por lo anterior, el propósito de la presente recopilación es presentar las aplicaciones de las técnicas espectroscópicas: ultravioleta-visible (UVVIS), IR, RMN, Espectrometría de Masas (EM), Emisión Óptica, Absorción Atómica, Raman, Fluorescencía, Láser, Rayos X, Mossbauer, Rayos Gama, Resonancia de Espín Electrónico, Impedancia y Dicroísmo Circular, usadas en la caracterización de suelos y con el fin de presentar otras técnicas alternativas a la tradicional química húmeda del suelo.

\section{TÉCNICAS ESPECTROSCOPICAS EN EL ANÁLISIS DE SUELO}

A continuación se presentan las diferentes técnicas espectroscópicas que son útiles en estudios de suelos y para cada una se describe sus inicios, fundamento, aplicaciones y algunos estudios de caso.

\section{Ultravioleta-Visible (UV- VIS)}

El primer espectrofotómetro UV VIS entró en uso general en la década de 1940 siendo una de las técnicas de laboratorio más comunes (Yücesoy, 2000). La espectroscopía UV trata con las interacciones de radiación ultravioleta con la muestra, está basada sobre la absorción de radiación electromagnética a longitudes de onda en el rango 200-400 nm, las moléculas que contienen electrones $\pi$ o electrones no enlazantes (electrones n) pueden absorber la energía en forma de luz ultravioleta o visible para excitar estos electrones a orbitales moleculares antienlazantes más altos. Los electrones más fácilmente excitados, es decir con menor diferencia de energía entre HOMO Y LUMO, mayor será la longitud de onda de la luz que pueden absorber. La espectroscopia UV sigue la ley de Beer-Lamberts (Kulkarni et al, 2014). La diferenciación en las señales del espectro de orden cero y obteniendo espectros de derivadas consecutivos, se logra la separación de picos sobrelapados, incrementando la selectividad sin separación del analito. Generalmente, un incremento en la sensibilidad de la determinación es lograda con un aumento en el orden de la derivada (Kuś et al, 1996).

El estudio del espectro UV-VIS de la materia orgánica del suelo (MOS) haciendo un extracto alcalino de la muestra (Saito y Seckler, 2014), ha permitido clasificar el humus en tipo $A, B, R p$ o $P$ considerando el $\Delta$ logK y la relación $E_{4} / E_{6^{\prime}}$ entre otras y ha informado del grado de humificación de la MOS (Cunha et al, 2009). La $A_{465}$ se relaciona con la primera fase del proceso de humificación y $A_{665}$ está relacionada a componentes bien humificados, de forma que valores bajos de $\mathrm{Q}_{4 / 6}\left(\mathrm{o}_{4} / \mathrm{E}_{6}\right.$ ) indican alta calidad de sustancias húmicas del suelo (SHS) (Fasurová y Pospíšilová, 2010). Esta técnica también ha sido útil en la caracterización de materia orgánica (MO), extractable de la solución del suelo (Hassouna et al, 2012). Se ha sugerido describir el espectro de absorción UV de MOS considerando tres bandas 
tipo gaussiana y relacionadas con las transiciones electrónicas de moléculas similares a benceno. Una banda muy intensa centrada en $180 \mathrm{~nm}$ (transición permitida $\pi-\pi^{\star}$ ), en $205 \mathrm{~nm}$ y $250 \mathrm{~nm}$ (afectada por presencia de funciones polares: hidroxilo, carbonilo, carboxilo), y en $280 \mathrm{~nm}$ (representa aromaticidad total, transición electrónica $\left.\pi-\pi^{\star}\right)$, común para arenos fenólicos, ácido benzoico, derivados de anilina, polienos e hidrocarburos aromáticos policíclicos con dos o más anillos (Purmalis y Klavins, 2013).

\section{Infrarrojo (IR)}

Con la construcción en 1930 del primer prototipo de espectrofotómetro IR se inicio un interés creciente por la espectroscopía infrarrojo (Derrick et al, 1999), siendo la técnica espectroscópica más usada en análisis de suelos (Nocita et al, 2015). La espectroscopía infrarrojo cercano (NIR, por su sigla en inglés) es un método espectrofotométrico que trata con las interacciones de radiación de infrarrojo cercano con la muestra. Se basa en la absorción de radiación electromagnética de longitudes de onda en el rango de 780-2500 nm. La absorción de radiación infrarroja depende sobre el cambio neto en el momento dipolar de la molécula como consecuencia de su movimiento vibracional. Cuando las vibraciones son acompañadas por un cambio en el momento dipolar y cuando la frecuencia de las vibraciones iguala la frecuencia de radiación infrarroja sucede una transferencia de energía neta desde la fuente de radiación a la molécula. Esto resulta en un cambio en amplitud de la vibración molecular. Esto es, la vibración absorbe la radiación infrarroja y la molécula es excitada a niveles energéticos superiores. Esta transmisión de energía puede ser medida como una relación de energía (reflectancia, absorción o transmitancia), contra la longitud de onda (Kulkarni et al, 2014). Dentro de las ventajas de la espectroscopía FTIR están: relativamente rápida y fácil de usar, se requiere poca o nula preparación de muestra, usa cantidades de muestra del orden de mg o menos. Algunas desventajas de esta espectroscopía son: control de las condiciones ambientales (p. e. humedad relativa) alrededor del instrumento que pueden causar variaciones en los espectros y son requeridos múltiples barridos de la misma muestra (Davis y Mauer, 2010).

Se ha caracterizado caolinita mediante FTIR (Saikia y Parthasarathy, 2010). El espectro de infrarrojo con transformada de Fourier (FTIR por sus siglas en inglés), de MOS ha permitido a) caracterizar las concentraciones de minerales arcillosos de suelos a partir de su perfil espectral (Bastidas y Carbonell, 2010), b) diferenciar caolinita de gibbsita, sin embargo FTIR ha sido poco informativa en la diferenciación de suelos bajo diferente cobertura, c) evidenciar el enriquecimiento de estructuras químicamente recalcitrantes con mayor funcionalización y pobre en grupos conteniendo nitrógeno al introducir especies arbóreas en suelos de pastura (Dick et al, 2011), d) estudiar el mecanismo de degradación en suelos de 2-hidroxi(2H)-1,4-benzoxazin-3(4H)-ona, un aleloquímico fitotóxico de las gramíneas (Oliveros et al, 2012) entre otras aplicaciones.

De otro lado, los análisis de infrarrojo cercano visible (VIS-NIR por sus siglas en inglés, 0,35-2,5 $\mu \mathrm{m}$ ), y infrarrojo medio (MIR por su sigla en inglés, 2,5$25 \mu \mathrm{m})$, se han usado para predecir propiedades del suelo como: color, composición mineral, MO y contenido de agua (hidratación, higroscopicidad y poros libres de agua), forma y cantidad de hierro, carbonatos, sales solubles, distribución de agregados y de tamaño de partícula (Shepherd, 2010), CO, $\mathrm{Ca}, \mathrm{Mg}, \mathrm{Na}, \mathrm{K}, \mathrm{P}, \mathrm{Al}$, pH (Bonett et al, 2015). Estudios en suelos con MIR también han permitido a) estimar contenido de limo, arena y arcilla del suelo (Linker, 2012; Bashagaluke et al, 2015), b) analizar rizósfera usando reflectancia total atenuada (ATR, por su sigla en inglés) cuyos espectros han servido para estudios taxonómicos de vegetales (Rewald y Meinen, 2013), 
c) caracterizar suelos (Linker, 2008) y d) caracterizar filosilicatos (Parikh et al, 2014).

La espectroscopía VIS-NIR se ha usado en estudios de remediación de suelos (Lu, 2013), carbonatación y salinización (Feyziyev et al, 2016) y estimación del contenido de MOS (Tian et al, 2013). La reflectancia de espectroscopía de reflectancia difusa por infrarrojo cercano visible (VIS-NIR-DRS por sus siglas en inglés) (700-2500 nm), desarrollada inicialmente para predecir carbono orgánico del suelo (COS), ha sido útil en el modelamiento de paisajes, agricultura de precisión, mapeo digital de suelos y monitoreo de COS para uso en secuestro y bonos de carbono (Shiferaw y Hergarten, 2014). Los análisis de espectroscopia de reflectancia difusa con infrarrojo cercano (NIR-DRS por su sigla en inglés) y análisis de regresión por mínimos cuadrados parciales ha permitido la cuantificación del carbono del suelo, con modelos de predicción (Amare et al, 2013; Camacho et al, 2014). la espectroscopia de infrarrojo cercano (NIRS), se ha usado, entre otros, en la determinación de hidrocarburos del petróleo, como contaminantes del suelo, además en el estudio de drenaje ácido de minería, el cual es un subproducto de la oxidación de disulfuro de pirita, mediante el estudio del contenido de azufre (Schwartz et al, 2011). Se ha registrado el uso de la espectroscopía de reflectancia con espectroscopía de infrarrojo cercano con visible (VNIR por su sigla en inglés) para predecir el contenido de arsénico en muestras de suelo (Lokhande y Deshmukh, 2016).

La reflectancia en la región de IR de onda corta (SWIR por sus siglas en inglés) ha sido útil para monitorear el contenido de N, P, S y K en plantas en combinación con reflectancia en la región VIS-NIR (Mahajan et al, 2014). El estudio del espectro de DR en la región infrarrojo con transformada de Fourier (DRIFT por su sigla en inglés) de la MOS ha mostrado bandas típicas en la región 3057-3055 cm-1 y en 2934-2928 $\mathrm{cm}^{-1}$ y cuya relación de absorbancias se ha denominado índice de aromaticidad, ya que expresa la relación entre el estiramiento de $\mathrm{C}-\mathrm{H}$ de grupos aromáticos y el estiramiento asimétrico axial de $\mathrm{C}-\mathrm{H}$ alifático respectivamente. De otro lado, la relación entre la absorbancia de la banda de absorción en la región $2928 \mathrm{~cm}^{-1}$ y en 1050-1080 cm $\mathrm{cm}^{-1}$ también ha permitido establecer un índice de hidrofobicidad que expresa la relación entre los grupos apolares $\left(\mathrm{CH}_{3}\right)$ y polares $(-\mathrm{OH}, \mathrm{C}-\mathrm{O})$ debido al estiramiento de $\mathrm{C}-\mathrm{H}$ de grupos aromáticos y el estiramiento asimétrico axial de $\mathrm{C}-\mathrm{H}$ alifático respectivamente. Finalmente, la relación entre las bandas de absorción 1.720-1.722/1.525 se denomina índice de reactividad, ya que expresa la relación entre el estiramiento $\mathrm{C}=\mathrm{O}$ de $\mathrm{COOH}$ y cetonas y el estiramiento del $\mathrm{C}=\mathrm{C}$ aromático (Cunha et al, 2009).

El análisis de datos obtenidos por técnicas basadas en sensores remotos ópticos tales como espectroscopia del suelo e imagenología hiperespectral han servido para caracterizar y monitorear variables del suelo. Estas técnicas han usado información espectral dentro de las regiones visible e infrarrojo cercano (VIS y NIR 400-1000 nm) e infrarrojo de onda corta (SWIR 1000-2500 nm). En éstas regiones espectrales los componentes orgánicos e inorgánicos, tales como arcillas, materia orgánica, óxidos de hierro o carbonato de calcio interactúan con la radiación electromagnética y producen señales características de absorción en espectros de reflectancia del suelo que pueden ser usadas para identificar propiedades del suelo cuando los suelos están expuestos a la superficie y la cubierta vegetal es baja, tal como sucede con la erosión (Schmid et al, 2016).

\section{Resonancia Magnética Nuclear (RMN)}

Los primeras aplicaciones de la espectroscopía de RMN se registraron en el año de 1946 convirtiéndose en una de las metodologías más útiles en diferentes campos del conocimiento, desde cinética hasta superconductividad (Becker, 1993). La 
principal limitación de la espectroscopía RMN es la baja sensibilidad en la detección y mayor consumo de tiempo, comparado a cristalografía de rayos $\mathrm{X}$ o espectroscopía de masas. En muchos casos la cantidad de muestra disponible es limitada o la solubilidad de la sustancia de interés es baja o se debe trabajar una solución diluida se debe usar debido a que la muestra tiende a agregarse a altas concentraciones. Aunque se usa un instrumento de alto costo y cuidado, la fuerza de la espectroscopía RMN consiste en generar datos para análisis estadístico de mezclas hasta permitir la determinación de estructuras tridimensionales para moléculas de interés biológico (Kovacs et al, 2005). Los minerales y materia orgánica son normalmente analizados por difracción de rayos X (XRD por su sigla en inglés), y métodos de química húmeda como cromatografía de exclusión por tamaño de alta eficiencia, pirólisiscromatografía de gases acoplado a espectrometría de masas o titulaciones. Sin embargo XRD requiere alto grado de cristalinidad de los minerales, en tanto que los análisis por química húmeda para $\mathrm{MO}$ necesitan tratamientos de muestra que pueden modificar la estructura y conformación de la MO. Contrariamente los análisis por RMN de estado sólido pueden ser aplicados directamente sobre la muestra de suelo para estudiar MO sin perturbar y minerales amorfos o la naturaleza de las interacciones entre MO y arcillas (Conte y Piccolo, 2007). Un núcleo puede ser considerado como una fuente de campo magnético $\left(B_{N}\right)$. La fuerza del $B_{N}$ es medida por un vector llamado momento magnético $(\mu)$, dirigido desde el polo sur al polo norte del campo. El $\mu$ se relaciona con el spin (I), mediante la expresión matemática $\mu=\gamma \mid h / 2 \pi$, donde $h / 2 \pi$ es la constante de planck y y es la razón giromagnética, que es una constante para cada núcleo. De otro lado, todos los momentos magnéticos de una población de núcleos son aleatoriamente orientados en un espacio de tres dimensiones en ausencia de cualquier campo magnético. Sin embargo, cuando los núcleos son colocados en un campo magnético (Bo), orientado $z$, sus momentos magnéticos son alineados a lo largo de la dirección del campo aplicado y el spin alrededor del eje z. después de la aplicación del campo magnético z, la energía de los spin nuclear es dividida en diferentes niveles según el numero cuántico magnético $(m)$, cuyos valores se relacionan con I. Al aumentar el campo magnético aplicado, es más grande la diferencia entre los niveles de spin nuclear. El fenómeno RMN está basado sobre la transición del spin nuclear de nivel de spin baja a alta energía. Solo los núcleos que tienen $I \neq 0$ son RMN activos o sensibles y pueden ser detectados. De otro lado, la sensibilidad a RMN es también directamente relacionada a valores de y y a la abundancia relativa. Así, los núcleos más sensibles de ser analizados por RMN son ${ }^{1} \mathrm{H},{ }^{19} \mathrm{~F},{ }^{31} \mathrm{P},{ }^{27} \mathrm{Al},{ }^{23} \mathrm{Na}$ y ${ }^{55} \mathrm{Mn}$ ya que éstos núcleos pueden tener sea, la más alta abundancia isotópica relativa o el mayor valor y (Conte y Piccolo, 2007).

Se ha usado RMN protónica de relajación para estudiar la distribución del tamaño de poro en el suelo, humectación, expansión o cambios en la condición macromolecular, que se basa en las interacciones entre moléculas de la materia orgánica del suelo y que puede servir para establecer la asociación de agua y otros compuestos (Bayer et al, 2010). Se ha revisado la determinación de $\mathrm{P}$ en suelo por resonancia magnética nuclear de isótopo de fósforo 31 (31P-RMN) (Cade-Menun, 2005). De otro lado, los resultados de análisis de espectros de ${ }^{31} \mathrm{P}-\mathrm{RMN}$ de extractos de suelos han reevaluado los índices diéster (Pdiéster/Pmonoéster y $P_{D N A} / P_{\text {noDNA }}$ ) relacionados con el origen del $\mathrm{P}$ orgánico del suelo indicando que no son universales (Makarov et al, 2005). La espectroscopía de resonancia magnética nuclear con ángulo mágico con polarización cruzada $\left({ }^{13} \mathrm{C}\right.$ NMR CPMAS por su sigla en inglés) es una técnica muy común en análisis de suelos. El espectro ${ }^{13} \mathrm{C}$ 
RMN en estado sólido se ha usado para estudiar la composición de MOS y sus fracciones. La combinación de $\mathrm{RMN}{ }^{1} \mathrm{H}$ en solución y $\mathrm{RMN}{ }^{13} \mathrm{C}$ de estado sólido ha proporcionado un análisis más detallado de la composición de la MOS; el parámetro denominado degradación alquilo/O-alquilo ha mostrado que la $\mathrm{MO}$ asociada a fracciones de arcilla estuvieron en estados más avanzados de degradación comparado con la $\mathrm{MO}$ asociada a las fracciones de suelo de densidad liviana (Clemente et al, 2012). Mediante el empleo de RMN en estado sólido, se estudió MOS de tres suelos destinados al cultivo de ceboIla larga a dos profundidades. Los espectros de 13C NMR CPMAS evidenciaron el orden respecto al tipo de carbonos que conforman la materia orgánica del suelo, determinando que el carbono resonante $\mathrm{N}$ - $\mathrm{y}$ O-alquilo y acetal dominó en toda la MOS obtenida; seguido de carbono aromático para los unos suelos y carbono alifático para otros suelos. Finalmente, el carbono $\mathrm{C}=\mathrm{O}$ fue el menos dominante en la MOS en todos los tres suelos caracterizados (Mosquera et al, 2010). La resonancia magnética de imágenes (RMI) ha permitido a) estimar el contenido de agua en suelos bajo pastura asociado a porosidad (Carrero et al, 2010), compactación (Carrero et al, 2012), b) monitorear como las raíces de la planta penetran el suelo (Antonsen et al, 2010) e ingieren agua (Pohlmeier et al, 2010), c) determinar propiedades conformacionales de ácidos fúlvicos (AF) y ácidos húmicos (AH) (Conte y Piccolo, 2007), d) crear mapas del contenido de MOS (Wang et al, 2010), e) detectar salinización del suelo (Yong et al, 2010), y f) realizar estudios de infiltración en suelos (Amin et al, 1998).

\section{ESPECTROMETRÍA DE MASAS (EM)}

Los primeros equipos de espectrometría de masas (EM) se remontan a 1912 cuando J. J. Thomson construyó el primer espectrómetro de masas y se empezaron a comercializar hacia 1942, este instrumento mide la relación masa/carga de los electrones, y cuyos desarrollos permitieron demostrar la existencia de isótopos y han permitido analizar macromoléculas de interés biológico usando técnicas de ionización como ionización y desorción de matriz asistida por láser (MALDI, por sus sigla en inglés) e ionización electrospray (ESI, por sus sigla en inglés) (Griffiths, 2008). Entre las desventajas de la EM están: se destruye la muestra, costoso, dificultad de introducir la muestra en un sistema de alto vacío y entre las ventajas están: se requiere poca muestra, alta sensibilidad y especificidad y consumo de tiempo (Neetu et al, 2012).

El primer paso en análisis de espectrometría de masas de compuestos es la producción de iones en fase gaseosa del compuesto de interés, por ejemplo por impacto electrónico, el ión molecular formado sufre fragmentaciones. Debido a este ión molecular es un catión radical con un número impar de electrones, éste puede fragmentar para dar un radical y un ión, con un numero par de electrones o una molécula y un nuevo radical catión. Estos dos tipos de iones tienen diferentes propiedades químicas. cada producto iónico primario derivado del ión molecular puede a su vez sufrir fragmentaciones así sucesivamente. Todos estos iones son separados en el espectrómetro de masas según su relación masa/carga y son detectados en proporción a sus abundancias (Griffiths, 2008).

Mediante cromatografía líquida acoplada con espectrometría de masas usando como interfase ionización química a presión atmosférica (LC/APCl/ MS por su sigla en inglés) se ha evaluado residualidad de imidacloprida en suelos (Bonmatin et al, 2003). Mediante EM de proporción isotópica (EMPI) se han estudiado isótopos de azufre del suelos (Luiza et al, 2012), y la producción de nuevo carbono del suelo derivado de pasturas $\mathrm{C}_{4}$ dentro de fracciones de agregados del suelo bajo pasturas productivas 
monitoreando ${ }^{13} \mathrm{C}$ (Fonte et al, 2014). Estudios relacionados con el proceso de denitrificación para formar óxido nitroso $\left(\mathrm{N}_{2} \mathrm{O}\right)$ en suelos y usando EMPI se midió la diferencia entre $\delta^{18} \mathrm{O}$ producido del $\mathrm{N}_{2} \mathrm{O}$ y del agua del suelo para establecer el parámetro $\delta^{18} \mathrm{O}\left(\mathrm{N}_{2} \mathrm{O} / \mathrm{H}_{2} \mathrm{O}\right)$ denominado diferencia de proporción isotópica relativa entre $\mathrm{N}_{2} \mathrm{O}$ y agua del suelo, el cual permite diferenciar denitrificación fúngica y bacteriana (Lewicka et al, 2016).

Estudios por EM de los isótopos ${ }^{13} \mathrm{C}$ estable y ${ }^{14} \mathrm{C}$ radiactivo sirvieron para estudiar las transformaciones de los residuos orgánicos frescos en MOS (Martínez et al, 2008). Mediante mediciones de ${ }^{14} \mathrm{C}$ por EM de aceleración se ha puesto en evidencia cómo el tamaño de partícula controla la recalcitrancia del carbono presente en la MOS (Marzaioli et al, 2009). La Termoquimiólisis acoplado a cromatografía de gases con espectrometría de masas (CGEM), proporciona información relacionada con grupos metoxilo, ácidos metilados, alcoholes, fenoles, derivados de lignina y esteres metílicos de ácidos grasos presentes en $\mathrm{SH}$. Esta técnica también aportó información asociada con el papel de los grupos quinona-hidroquinona como mediadores redox de $\mathrm{SH}$, como mediadores de la reducción de contaminantes orgánicos (Tadini et al, 2015).

\section{EMISIÓN ÓPTICA Y ABSORCIÓN ATÓMICA}

A mediados de la década de 1940 aparecieron los espectrómetros de lectura directa, que proporcionaron análisis multielemento de alta velocidad a la industria metalúrgica (Willis, 1993). La espectrofotometría de AA se basa en la medición de la concentración por detección de la absorción de radiación electromagnética por átomos más que de moléculas. En el instrumento la fuente usual de luz, denominada como lámpara de cátodo hueco, consiste de una cámara hermética conteniendo un ánodo, un cátodo cilíndrico y un gas inerte, tales como helio o argón. Cuando se aplica voltaje, el gas de llenado es ionizado. Los iones atraídos al cátodo colisionan con el metal y causa que los átomos del metal sean excitados. Cuando ellos vuelven al estado basal la luz emitida es característica del metal en el cátodo. Generalmente una lámpara separada es requerida para cada metal, es decir, una lámpara de cátodo hueco de cobre es usada para medir cobre. la muestra analizada debe contener el metal reducido en estado atómico vaporizado (Drees y Wu, 2010).

El principal problema en preparación de las muestras para análisis de trazas por AA es el riesgo de contaminación, por el grado de reactivo usado, recipiente de la muestra, pasos de digestión o dilución de la muestra (Ramadan, 2011). La espectrofotometría de AA es sensible y precisa. Es rutinariamente usada para medir la concentración de metales traza que no son fácilmente excitados. Es generalmente más sensible que emisión de llama debido a la gran cantidad de átomos producidos en la llama de propano o aire-acetileno que permanecen en el estado basal disponibles para absorción de luz. La AA es exacta, precisa y específica. Una desventaja es la inhabilidad de la llama para disociar muestras en átomos libres. por ejemplo, el fosfato puede interferir con análisis de calcio, lo cual se puede superar adicionando óxido o cloruro de lantano o estroncio. Otro posible problema es la ionización de átomos siguiendo la disociación por la llama, lo cual se minimiza disminuyendo la temperatura de la llama (Drees y Wu, 2010)

La espectrometría de absorción atómica es la técnica clásica para determinar base totales y elementos menores del suelo (Zamudio et al, 2006). Mediante el uso de espectroscopia de emisión óptica con plasma inductivamente acoplado (ICPOES, por su sigla en inglés) se determinó $P$ mineralizado de suelos tratados con enmiendas orgánicas 
(Haney et al, 2015). El arsénico en suelos se ha determinado usando EAA, espectroscopia de fluorescencia atómica (EFA) y análisis de activación de neutrones (NAA, por su sigla en inglés) (Alonso et al, 2014).

\section{RAMAN}

Hacia finales de la década de 1920 se publicaron los primeros resultados de la utilización de la espectroscopía Raman, la cual es actualmente usada en química clínica, estudio de explosivos, análisis de fármacos entre otros. Es un técnica dispersiva basada en el efecto Raman, en el cual la frecuencia de una pequeña fracción de radiación dispersada es diferente de la frecuencia de radiación incidente monocromática y se fundamenta en la dispersión inelástica de radiación incidente a través de sus interacciones con moléculas en vibración de manera que esta técnica explora las vibraciones moleculares. En espectroscopía Raman, la muestra es iluminada con haz de láser monocromático el cual interactúa con moléculas de la muestra y origina una luz dispersada. Ésta luz dispersada tiene una frecuencia diferente respecto de la luz incidente y se usa para construir el espectro Raman, el cual puede cubrir un rango de $4000-10 \mathrm{~cm}^{-1}$. El espectro Raman es más simple que su contraparte IR ya que en Raman normal las bandas de tipo sobretonos, de combinación y de diferencia son raras. La baja sensibilidad debida a una débil dispersión Raman es el principal problema asociado con esta técnica, sin embargo la sensibilidad se puede aumentar usando espectroscopía Raman de resonancia y espectroscopia Raman de superficie aumentada (Bumbrah y sharma, 2015).

Raman es una técnica de espectroscopía vibracional que ha sido útil para estudiar humedad del suelo en tiempo real. En el espectro Raman de agua sobresalen las bandas de tensión simétrica en $3652 \mathrm{~b} \mathrm{~cm}^{-1}$, tensión simétrica en $3756 \mathrm{~cm}^{-1}$ y flexión simétrica en $1595 \mathrm{~cm}^{-1}$. Al comparar éstas bandas con el espectro Raman de la muestra de suelo, se observaron dos bandas $\mathrm{OH}$ en 3355 y $3583 \mathrm{~cm}^{-1}$. La banda en $3355 \mathrm{~cm}^{-1}$ se asocia a la presencia de agua (Ćorluka et al, 2011). También se ha usado espectroscopia Raman en estudios de clasificación de suelos asociada a herramientas quimiométricas (Luna et al, 2014)

\section{FLUORESCENCIA}

Hacia 1955 se desarrolló el primer prototipo de espectrofluorómetro, el cual a diferencia de los fluorómetros anteriores permitían variar la longitud de onda de la luz de excitación así como medir la intensidad y longitud de onda de la luz fluorescente emitida (Udenfriend, 1995). Los espectros de fluorescencia y rendimiento cuántico son mas dependientes sobre el ambiente que de los espectros de absorción y coeficientes de extinción. Los factores que afectan las propiedades fluorescentes son: polaridad del solvente, $\mathrm{pH}$ del medio acuoso, dilución del fluoróforo y temperatura (Sauer et al. 2011). La fluorescencia es el resultado de un proceso de tres etapas en la capa electrónica de ciertas moléculas (generalmente hidrocarburos poliaromáticos o heterociclos) llamados fluoróforos, los tres procesos involucrados en fluorescencia son a) excitación: un fotón de energía huex es suministrado por una fuente externa tal como una lámpara incandescente o un láser y absorbido por el fluoróforo. La energía es usada para empujar un electrón del estado basal a un estado excitado. La absorción ocurre en cerca de $\left.1 \mathrm{fs}\left(10^{-15} \mathrm{~s}\right), \mathrm{b}\right)$ transición no radiante: los electrones gastan un tiempo (1-10 ns) en el estado excitado. Durante este tiempo, el fluoróforo sufre cambios conformacionales y es sujeto a una multitud 
de posibles interacciones con su ambiente molecular (p. e. colisiones). Estos procesos tienen dos aspectos relevantes: primero la energía del subestado inicial es parcialmente disipada, llevando a un estado excitado singlete relajado del cual se origina la emisión de fluorescencia. Segundo, no todas las moléculas inicialmente excitadas por absorción vuelven al estado basal por la fluorescencia; otros procesos tales como aplacamiento colisional "collisional quenching", transferencia de energía de fluorescencia y cruzamiento intersistemas también pueden despoblar el subestado inicial sin emitir un fotón y c) emisión de fluorescencia: finalmente con cierta probabilidad un fotón de energía $h v_{\mathrm{ft}}$ es emitido, retornando el fluoróforo a su estado basal. Debido a la energía de disipación durante el tiempo de vida del estado excitado (relajación no radiante), entonces la energía de este fotón es menor y por tanto de mayor longitud de onda que la del fotón de excitación $h v_{\text {ex }}$. La diferencia de energía está relacionada al desplazamiento de stokes, el cual es la diferencia en longitud de onda entre los máximos de absorción y emisión (Patterson et al, 2001).

En análisis de suelos se han registrado espectros de fluorescencia de emisión, excitación y sincrónico. La prolongada longitud de onda para los picos de fluorescencia de sustancias húmicas indican la presencia de anillos aromáticos condensados y otros sistemas de enlace insaturado, un alto grado de conjugación y grupos aceptores de electrones como grupo carbonilo y carboxilo. La corta longitud de onda de los principales picos de fluorescencia de lignohumatos indica presencia de componentes estructurales simples de amplia heterogeneidad molecular y bajo peso molecular, bajo tamaño molecular, bajo grado de policondensación aromática, bajo nivel de fluoróforos conjugados y bajo grado de humificación (Enev et al, 2014). La fluorescencia sincrónica puede determinar todos los picos de fluorescencia de la muestra, el número de picos principales es igual al número de fluoróforos presentes en la estructura húmica. Las longitudes de onda cortas de picos de fluorescencia principales son típicos de AF y longitudes de onda largas son típicas de AH con una baja diferencia constante $\Delta \lambda$ (Fasurová y Pospiśsilová, 2010). La fluorescencia total de rayos $X$, abreviada TXRF (por su sigla en inglés) proporciona análisis de todos los elementos. Los perfiles de concentración total de elementos son usados como huella digital del suelo, establecimiento de diferencias mineralógicas claves y como entrada para funciones de pedotransferencia (Shepherd, 2010; Towet et al, 2013). Con respecto a la espectroscopia de fluorescencia 3D, también denominada espectroscopia de luminiscencia total ( $T L$, por sus sigla en inglés) es una técnica para caracterizar y diferenciar $\mathrm{AH}$ y $\mathrm{AF}$ de la $\mathrm{MOS}$ en relación a su naturaleza y origen (Nogueira et al, 2009). Se ha usado la fluorescencia de matriz de emisiónexcitación asociada a la electroforesis capilar en la caracterización de sustancias húmicas del suelo ( $\mathrm{He}$ et al, 2008). La espectroscopía de fluorescencia ha sido usada para derivar mediciones de rasgos característicos de raíces en suelos, de forma que se separan las raíces de suelo mediante un sistema de elutriación hidroneumática y se evalúan las propiedades de emisividad de fluorescencia de suelo y raíces (Wasson et al, 2016).

\section{LÁSER}

La primera publicación sobre amplificación de luz por emisión estimulada de radiación (láser, por su sigla en inglés) fue en 1958 (Bertolotti, 2013). El láser es un mecanismo para producir un haz de luz monocromática en la cual todas las ondas están en fase. Los instrumentos con láser tienen cuatro componentes a) medio activo: puede ser un cristal sólido como rubí o $\mathrm{Nd}: Y A G$, o gases como $\mathrm{CO}_{2}$ 
- $\mathrm{He} / \mathrm{Ne}$ o semiconductores como GaAs. el medio activo contiene átomos cuyos electrones pueden ser excitados a un nivel de energía metaestable por una fuente de energía b) mecanismo de excitación: suministra energía dentro del medio activo por métodos ópticos, eléctricos o químicos c) espejo de alta reflectancia: un espejo que refleja el 100\% de la luz láser y d) espejo parcialmente transmisivo. Cuando se aplica energía a un medio activo láser, los electrones son elevados a un nivel electrónico inestable entonces espontáneamente decaen a un estado metaestable menor y relativamente de larga vida. Los electrones en este estado no deben espontáneamente retornar a su nivel de energía basal, por lo tanto es posible suministrar grandes cantidades de energía dentro del material así obteniendo una inversión de la población en la cual muchos de los átomos están en estado metaestable. Después de esto la acción láser es iniciada por un electrón el cual espontáneamente vuelve a su estado basal produciendo un fotón. Si el fotón liberado es de exactamente la longitud de onda determinada éste debe estimular un átomo en un estado metaestable para emitir un fotón de la misma longitud de onda. La técnica láser se debe usar con cuidado dado el posible daño ocular al operador, los altos voltajes requeridos para potenciar el láser, intoxicación con colorantes para láser y la manipulación de fluídos criogénicos (Drewsen, 2002).

La espectroscopía de difracción láser (LDS, por su sigla en inglés), se ha usado para determinar textura del suelo usando un rango detectable de 0.01-3000 $\mu \mathrm{m}$ (Shepherd, 2010), y siendo mejor que bouyoucos para predecir las propiedades hidráulicas de suelos (Segal et al, 2009). La espectroscopía de plasma inducido por láser (LIBS por sus siglas en inglés) detecta a) elementos metálicos contaminantes, b) clasifica los tipos de suelos y ayuda a caracterizar fertilizantes (López et al, 2011), c) detecta carbono en suelo (BeIkov et al, 2010), y d) determina bases totales y elementos menores del suelo (Pareja et al, 2013).

\section{RAYOS X}

El descubrimiento de los rayos X en 1895 fue el inicio de grandes cambios en el entendimiento del mundo físico (Assmus, 1995). Los fotones de rayos $X$ son una forma de radiación electromagnética producida siguiendo la expulsión de un electrón de orbital interno y subsecuente transición de electrones de orbitales atómicos desde estados de alta a baja energía. Cuando un haz monocromático de fotones de rayos $X$ cae dentro de un espécimen dado, se puede presentar absorción, dispersión o fluorescencia. Los protones dispersados coherentemente pueden sufrir subsecuente interferencia llevando a su vez a la generación de máximos de difracción. Los tres fenómenos antes mencionados son la base de tres importantes métodos de rayos $\mathrm{X}$ : la técnica de absorción, la cual es la base del análisis radiográfico, el efecto dispersante, el cual es la base de la difracción de rayos $X$ y el efecto de fluorescencia, el cual es la base de espectrometría de fluorescencia de rayos X (XRF por su sigla en inglés), (Jenkins, 2000).

La espectroscopia de absorción de rayos $X$ de estructura fina (XAFS, por sus siglas en inglés) permite elucidar mecanismos de sorción de Co, Cr, Mn, Ni y Zn en suelos (Sparks, 2006). La espectroscopía de absorción de rayos $X$ en estructuras de borde cercano (XANES por su sigla en inglés), se ha usado para estudiar la organización estructural de suelo saturado con $\mathrm{Cu}^{+2}$ y $\mathrm{Zn}^{+2}$ determinando el mecanismo de sus interacciones con el suelo y todas las uniones químicas que toman lugar (Nevidomskaya et al, 2014), y la nitración de estructuras aromáticas para la producción de $\mathrm{N}_{2} \mathrm{O}$ en rizósfera (Gillespie et al, 2007). Se ha cuantificado $\mathrm{Ni}, \mathrm{Cr}, \mathrm{Cd}$, Cu y Pb en suelos contaminados usando una variante de espectroscopia de rayos $X$ de energía dispersiva (EDX por su sigla en inglés), como es la espectrometría de fluorescencia de rayos $X$ con energía dispersiva (EDXRF por su sigla en inglés) (Fierãscu et al, 2007). En la técnica de difracción 
por rayos $\mathrm{X}$, (XRD por su sigla en inglés) los espectros crudos (conteo vs ángulo) de estudios mineralógicos de las muestras de suelo pueden ser usados directamente como entradas para funciones de pedotransferencia (Shepherd, 2010). Con XRD se han identificado minerales ricos en arcillas, determinado propiedades de hidratación, grado de cristalinidad y desviaciones de la estructura nativa (Das et al, 2014; Haque et al, 2013). La espectroscopia de fotoelectrones emitidos por rayos X (XPS por su sigla en inglés), o espectroscopía electrónica de análisis químico (ESCA, por su sigla en inglés) reportó composición elemental de la superficie del suelo, O (65.14 \%), Si (15.79), Al (7.53), C (5.96), Mg (2.11), Ca (0.82) y N (0.68) (Ogundalu y Oyekan, 2014). La espectroscopía de rayos $X$ de estructura fina y borde cercano (NEXAFS por su sigla en inglés) y Fe $\mathrm{K}$ edge XAFS se han utilizado para monitorear los cambios en reactividad de minerales con hierro en suelo luego de aplicaciones por largo tiempo de fertilizantes y estiércol (Huang et al, 2016).

\section{RAYOS Y}

Los cimientos de la espectrometría de rayos gama se dieron en 1914 con los trabajos de Rutherford y Andrade (Deslattes, 2000). Los rayos gama son emitidos de núcleos radioactivos en sus procesos de descomposición, un rayo gama tiene una energía definida y un núcleo radioactivo emite muchos rayos gama con diferente energía mientras que otros solo emiten un rayo gama con una energía. Midiendo la energía de los rayos gama es posible deducir de cual isótopo éstos son emitidos una vez las energías son bien conocidas para todos los núcleos radioactivos. Se sabe como ${ }^{137} \mathrm{Cs}$ es producido en el reactor durante la irradiación tanto como la energía de su rayo gama. Se puede medir rayos gama con esa energía particular entonces podemos cuantificar ${ }^{137} \mathrm{Cs}$ en ese material (Willman, 2006).
Se ha usado espectroscopia gama ( $\mathrm{y}$ ) para evaluar suelos contaminados con radionúclidos de uranio luego de operaciones militares, determinando ${ }^{238} \mathrm{U}$ y ${ }^{235} \mathrm{U}$. Los resultados indicaron que la fuente de emisión edáfica de rayos gama alcanzó $6.5 \mu \mathrm{Sv} / \mathrm{h}$ (Anagnostakis et al, 2001). En suelos de Iraq, se ha evaluado niveles de radiactividad natural debida a radionúclidos como ${ }^{238} \mathrm{U},{ }^{232} \mathrm{Th}$ y ${ }^{40} \mathrm{~K}$ mediante espectroscopía de rayos gama hallándose que la velocidad de la dosis absorbida fue 17.558 nGy/h, el cual es un valor bajo respecto a la media mundial (55 nGy/h) e indicando que los suelos estudiados emiten una baja radiación natural pero sin riesgo radiológico para la población humana (Assie et al, 2016).

\section{MÖSSBAUER}

En 1957, Mössbauer descubrió que un núcleo en un sólido puede algunas veces emitir y absorber rayos gama sin retroceso. El nivel de energía de un núcleo situado en un átomo y en un sólido son modificados por el ambiente del núcleo. La espectroscopía Mössbauer es una técnica que permite describir estos niveles de energía midiendo la dependencia de la energía de la absorción resonante de los rayos gama Mössbauer por el núcleo. Experimentalmente la espectroscopía Mössbauer incluye una fuente radioactiva conteniendo el isotopo Mössbauer en un estado excitado y un material en estudio, el cual contiene el mismo isotopo en su estado basal (Dickson y Berry, 1986).

La espectroscopia Mössbauer (MS, por sus siglas en inglés), identifica óxidos, hidróxidos y otros minerales que contienen hierro de suelo y arcillas (Bustos et al, 2012). La combinación de técnicas como XRD y MS en estos análisis de suelos es necesario ya que los componentes mineralógicos que se observan en MS no son visualizados por XRD, debido a que se encuentran en estado amorfo o baja concentración 
Tabla 1. Parámetros de análisis de suelos evaluados mediante diferentes técnicas espectroscópicas.

\begin{tabular}{|c|c|c|}
\hline Parámetro & Espectroscopía & Referencia \\
\hline \multirow{5}{*}{ Materia orgánica } & UV VIS & Saito y Seckler, 2014 \\
\hline & RMN & Clemente et al, 2012 \\
\hline & ESR & Santos et al, 2013 \\
\hline & CD & Fan et al, 2004 \\
\hline & IR & Shiferaw y Hergarten, 2014 \\
\hline \multirow{2}{*}{ Carbono orgánico } & $\mathrm{RMN}$ & Conte y Piccolo 2007 \\
\hline & Laser & Belkov et al, 2010) \\
\hline Cadmio, Plomo, Cobre & Rayos $\mathrm{x}$ & Fierãscu et al, 2007 \\
\hline $\mathrm{pH}$ & IR & Bonett et al, 2015 \\
\hline \multirow{2}{*}{ Arsénico } & IR & Lokhande y Deshmukh, 2016 \\
\hline & EFA & Alonso et al, 2014 \\
\hline Nitrógeno & $\mathrm{IR}$ & Mahajan et al, 2014 \\
\hline \multirow{3}{*}{ Fósforo } & IR & Mahajan et al, 2014 \\
\hline & RMN & Cade-Menun 2005 \\
\hline & $\mathrm{ICP}$ & Haney et al, 2015 \\
\hline Azufre & IR & Mahajan et al, 2014 \\
\hline \multirow{4}{*}{ Sustancias húmicas } & RMN & Conte y Piccolo, 2007 \\
\hline & EM & Tadini et al, 2015 \\
\hline & fluorescencia & Enev et al, 2014 \\
\hline & ESR & Melo et al, 2011 \\
\hline Imidacloprida & EM & Bonmatin et al, 2003 \\
\hline${ }^{32} \mathrm{~S},{ }^{33} \mathrm{~S},{ }^{34} \mathrm{~S},{ }^{36} \mathrm{~S}$ & EM & Luiza et al, 2012 \\
\hline${ }^{13} \mathrm{C}$ & EM & Fonte et al, 2014 \\
\hline${ }^{18} \mathrm{O}$ & EM & Lewicka et al, 2016 \\
\hline${ }^{238} U y^{235} U$ & Gama & Anagnostakis et al, 2001 \\
\hline${ }^{238} \mathrm{U},{ }^{232} \mathrm{Th} \mathrm{y}{ }^{40} \mathrm{~K}$ & Gama & Assie et al, 2016 \\
\hline \multirow{2}{*}{ Hierro } & Rayos $x$ & Huang et al, 2016 \\
\hline & Mössbauer & Bustos et al, 2012 \\
\hline Fosfatasa ácida & $C D$ & Huang et al, 2009 \\
\hline
\end{tabular}




\begin{tabular}{|c|c|c|}
\hline ADN & CD & Cai et al, 2006 \\
\hline \multirow{3}{*}{ Minerales } & IR & Bonett et al, 2015 \\
\hline & Laser & Pareja et al, 2013 \\
\hline & Rayos $x$ & Towet et al, 2013 \\
\hline \multirow{2}{*}{ Arcillas } & IR & Saikia y Parthasarathy, 2010 \\
\hline & RMN & Conte y Piccolo, 2007 \\
\hline Color & IR & Shepherd, 2010 \\
\hline \multirow{4}{*}{ Humedad } & IR & Shepherd, 2010 \\
\hline & $\mathrm{RMN}$ & Carrero et al, 2010 \\
\hline & Raman & Ćorluka et al, 2011 \\
\hline & EIS & Li et al, 2016 \\
\hline Compactación & RMN & Carrero et al, 2012 \\
\hline \multirow{2}{*}{ Textura } & IR & Bashagaluke et al, 2015 \\
\hline & Laser & Shepherd, 2010 \\
\hline Filosilicatos & IR & Parikh et al, 2014 \\
\hline Porosidad & RMN & Bayer et al, 2010 \\
\hline Infiltración & RMN & Amin et al, 1998 \\
\hline \multirow{3}{*}{ Rizósfera } & ATR & Rewald y Meinen, 2013 \\
\hline & RMN & Antonsen et al, 2010 \\
\hline & fluorescencia & Wasson et al, 2016 \\
\hline
\end{tabular}

UV-VIS: ultravioleta.visible, RMN: resonancia magnética nuclear, ESR: electronic spin resonance, CD: circular dichroism, IR: infrarojo, EFA: espectroscopia de fluorescencia atómica, ICP: ionization coupled plasm, EM: espectrometría de masas, ADN: ácido desoxiribonucléico, EIS: electrochemical impedance spectroscopy, ATR: Attenued total reflectance.

y los componentes mineralógicos vistos por XRD y que no son observados por MS, se debe a que no contienen hierro, por lo cual pasan desapercibidos por esta última técnica (Trujillo et al, 2011).

\section{RESONANCIA DE ESPÍN ELECTRÓNICO}

En 1921, Gerlach y Stern observaron que un haz de átomos de plata se dividía en dos líneas cuando este estaba sujeto a un campo magnético presentando un efecto Zeeman anormal. La comprensión de este fenómeno llevo a la resonancia de espín electrónico la cual está basada sobre transiciones entre estados cuantizados del momento magnético resultante. La técnica es poco común, comparada con RMN, debido a la ausencia de sistemas paramagnéticos ya que la formación de un enlace químico está asociado al pareamiento electrónico y aun spin electrónico general igual a cero. la espectroscopía 
de espín electrónico (ESR), o resonancia electrónica paramagnética (EPR), es una técnica cuya radiación da información acerca de las vecindades de especies químicas que tienen uno o más electrones desapareados (radicales libres orgánicos e inorgánicos o complejos inorgánicos poseyendo un metal de transición). En EPR se trabaja con el spin electrón excitado mientras que en RMN se usa el spin de núcleos atómicos (Junk, 2012).

La ESR se ha usado en estudios de la MOS asociado a recuperación de suelos de explotación petrolera (Santos et al, 2013). Estudios por ESR mostraron que la alta concentración de radicales libres tipo semiquinona en suelo bajo cultivo fue consistente con la frecuente quema realizada antes de sembrar observándose incremento en la aromaticidad de ácidos húmicos $(\mathrm{AH})$ con mayor concentración de radicales libres semiquinona (Melo et al, 2011).

\section{DICROÍSMO CIRCULAR}

Hacia 1930 se empezaron a formalizar los aspectos teóricos relacionados con el dicroísmo circular (CD), fenómeno previamente registrado por Faraday como rotación magneto-óptica. El fenómeno es observado cuando la materia ópticamente activa absorbe luz polarizada circular hacia la izquierda y hacia la derecha con una pequeña diferencia. el equipo e CD debe medir absorbancia en el UV lejano (<190 nm). Las diferencias de absorbancia son del orden de $10^{-4}$, con una elipticidad de $0.01^{\circ}$. CD es una función de la longitud de onda y los espectros $C D$ de distintos tipos de macromoléculas son diferentes, permitiendo su identificación. Debido a que la quiralidad es inducida por campo magnético estático se puede usar $C D$ para identificación de compuestos no quirales. Es una técnica costosa como RMN, AA, considerando su inversión inicial (Štěpánek y Bouř, 2011).
Estudios con dicroísmo circular (CD, por sus siglas en inglés) de MOS mostraron que la persistencia de estructuras peptídicas preexistentes presentaron resistencia a la degradación mientras la presencia de aminoácidos completamente marcados sugirió incorporación masiva de péptidos nuevamente sintetizados en SHS (Fan et al, 2004). Con CD se ha estudiado la conformación de fosfatasa ácida sobre arcillas del suelo. Los resultados mostraron que la fosfatasa ácida cambió de forma desordenada a ordenada durante el ciclo de adsorción/desorción (Huang et al, 2009). Se han estudiado los fenómenos de adsorción, desorción y degradación de ADN por nucleasas en suelo y arcilla. El ADN cambió de la forma B a la forma C, observado por CD, cuando fue desorbido de caolinita. Se concluyó que la presencia de minerales proporcionó protección al acido desoxiribonucleico (ADN) contra degradación por DNAsa I (Cai et al, 2006).

\section{ESPECTROCOPIA DE IMPEDANCIA}

La espectroscopía de impedancia electroquímica (EIS, por su sigla en inglés), considera la ley de Faraday para caracterizar un proceso químico en termino de medición eléctrica. La impedancia electroquímica es la respuesta de un sistema electroquímico a un potencial aplicado. Es de notar que la respuesta del sistema electroquímico no es lineal (Lasia, 1999).

Se ha determinado in situ la conductividad eléctrica del suelo usando espectroscopía de impedancia electroquímica con valores de humedad entre 9.1-37.5\% según su resistencia óhmica. Se encontró una correlación significativa $\left(R^{2}=0.896, p<0.01\right)$ entre la conductividad del suelo y el contenido de humedad (Li et al, 2016). 


\section{CONSIDERACIONES GENERALES}

Como se ha observado, la espectroscopia no es sólo útil en la elucidación de compuestos puros sino que también ha proporcionado información valiosa en la caracterización de componentes/parámetros del suelo (Tabla 1 ) ya que ha permitido estudiar el componente orgánico, en pequeña proporción muchas veces en la fase mineral del suelo. Se puede estudiar AH o AF por UV VIS, IR, RMN, EM, fluorescencia, ESR y luminiscencia total logrando una caracterización más detallada de la estructura orgánica de la MOS y se pueden monitorear los cambios que se suceden en el suelo durante la mineralización/humificación. Igualmente el estudio del contenido de humedad del suelo se puede realizar, en tiempo real, mediante análisis de IR, RMN y Raman. Los estudios de minerales en suelos se han realizado usando técnicas espectroscópicas como Mösbauer, rayos gama, rayos $X$, láser como alternativas a las técnicas clásicas de emisión óptica y AA. Es importante resaltar el uso de CD y RMI para evaluar aspectos conformacionales de enzimas en suelos, como una aproximación al entendimiento de la interacción sustrato-receptor en la actividad catalítica y las interacciones en el complejo organomineral, respectivamente. La determinación de isótopos de algunos elementos mediante EM, RMN y rayos gama ha sido otra estrategia para evaluar aspectos en suelos, tales como degradación. Como se observa la MOS es el componente del suelo más estudiado por espectroscopía. Finalmente la espectroscopia láser e IR emergen como una alternativa a la tradicional determinación de textura por bouyoucos. Es evidente de la presente revisión que la espectroscopia IR es la más adecuada para redireccionar el trabajo en extensión en estudios de fertilidad de suelos ya que de bajo costo, junto al análisis quimiométrico puede estimar gran cantidad de parámetros de física y química del suelo, tiene relativamente manejo simple de la instrumentación, se puede trabajar la muestra en fase líquida y sólida requiriendo poco manejo previo de la misma y necesita poca inversión económica inicial comparado con RMN. La incorporación de los análisis IR en servicios de extensión para el sector agrícola Colombiano seguiría el enfoque sugerido por Nocita et al, (2015) en cuanto a la disminución de las técnicas contaminantes de química húmeda y buscar su menor impacto en el ambiente. Es de notar que bajo este enfoque ya existen experiencias en el agro Colombiano relacionados considerando los desarrollos tecnológicos en agricultura comercial a través del uso de sensores e imágenes satelitales (Adamchuk et al, 2004), los cuales poco a poco se han ido incorporando en el cultivo de café (Urbano, 2013), durazno (Jiménez et al, 2010), y de palma de aceite (Lizarazo y Alfonso, 2011), en Colombia.

\section{CONCLUSIONES}

La espectroscopía infrarrojo es la técnica más pertinente para incorporar en los análisis de fertilidad de suelos en Colombia considerando su versatilidad, bajo costo y reproducibilidad. Asociando los datos de IR con el uso de análisis quimiométrico se pueden lograr estimaciones de parámetros edáficos con alto grado de certeza, con lo cual se genera una nueva estrategia de trabajo en laboratorio ambientalmente más amigable. 


\section{REFERENCIAS}

1 Adamchuk VI, Hummel JW, Morgan MT, Upadhyaya SK. 2004. On-the-go soil sensors for precision agriculture. Computers and Electronics in Agriculture, 44: 71-91.

2 Alonso DL, Latorre S, Castillo E, Brandao P. 2014. Environmental ocurrence of arsenic in Colombia: A review. Environmental pollution, 186:272-281.

3 Amare T, Hergarten C, Hurni H, Wolfgramm B, Yitaferu B, Selassie Y. G. 2013. Prediction of soil carbon for Ethiopian highlands using soil spectroscopy. Hindawi publishing corporation. ISRN Soil Science. Vol 2013 Article ID 720589, 11 pages.

4 Amin M, Hall L, Chorley R, Richards K. 1998. Infiltration into soils, with particular reference to its visualization and measurement by magnetic resonance imaging (MRI). Progress in Physical Geography, 22: 136p.

5 Anagnostakis MJ, Hinis EP, Karangelos DJ, Petropoulos NP, Rouni PK, Simopoulos SE, Zunic ZS. 2001. Determination of depleted uranium in environmental samples by gamma spectroscopic techniques. Archive of oncology, 9: 231-236.

6 Antonsen F, Johnsson A, Futsaether C, Krane J. 2010. Nuclear magnetic resonance imaging in studies of gravitropism in soil mixtures. New phytologyst, 142: 59-66.

7 Armenta S, Guardia M. 2014. Vibrational spectroscopy in soil and sediment analysis. Trends in Environmental Analytical Chemistry, 2: 43-52.

8 Assie, A, Abbas OAJ, Jasim AS, Al-Mashhadani AH. 2016. Advances in Applied Science Research, 7: 35-41.

9 Assmus A. 1995. Early history of $x$ rays. Beam Line, summer. 10-24.
10 Bashagaluke J, Nshobole N, Fataki D, Mochoge B, Mugwe J, Walangululu J. 2015. Application of infrared technique in soil properties'characterization in south Kivu province of DR Congo. African Journal of Food and Technology, 6: 58-67.

11 Bastidas OE, Carbonell JA. 2010. Caracterización espectral y mineralógica de los suelos del valle del río Cauca por espectroscopía visible e infrarroja (400-2500 nm). Agronomía Colombiana, 28: 291-301.

12 Bayer J, Jaeger F, Schaumann G. 2010. Proton Nuclear Magnetic Resonance (NMR) Relaxometry in Soil Science Applications. The Open Magnetic Resonance Journal, 3: 15-26.

13 Becker ED. 1993. A brief history of nuclear magnetic resonance. Analytical Chemistry, 65: 295A-302A.

14 Belkov M, Burakov V, Giacomo A, Kiris V, Raikov S, Tarasenko N. 2010. Laser induced breakdown spectroscopy for rapid detection of carbon in soils. Publications of the Astronomical Observatory of Belgrade, 89: 173-176.

15 Bertolotti M. 2013. 1962-2012. : What does it mean fifty years in laser research? Romanian Reports in Physics 65: 619-637.

16 Bonett JP, Camacho TJH, Ramirez LL. 2015. Mid infrared spectroscopy for the estimation of some soil properties. Agronomia Colombiana, 33: 99-105.

17 Bonmatin J, Moineau I, Charvet C, Feche ME, Bengsch E.R. 2003. A LC/APCl-MS Method for Analysis of Imidacloprid in soils, in plants, and in pollens. Analytical Chemistry, 75: 2027-2033. 
18 Bumbrah GS, Sharma, RM. 2015. Raman spectroscopy-Basic principle, instrumentation and selected applications for the characterization of drugs of abuse. Egyptian Journal of Forensic Sciences. In press. doi:10.1016/j.ejfs.2015.06.001

19 Bustos RH, Oyola LD, Rojas MYA, Rivera PM, Pérez AGA. 2012. Characterization of mineral phases of agricultural soil samples of Colombian coffee using Mossbauer spectroscopy and $X$ ray diffraction. Hyperfine interactions. Doi: 10.1007/ s10751-012-0573-z.

20 Cade-Menun B. 2005. Characterizing phosphorus in environmental and agricultural samples by P-31 nuclear magnetic resonance spectroscopy. Talanta, 66: 359-371.

21 Cai P, Huang OY, Zhang XW. 2006. Interactions of DNA with clay minerals and soils colloidal particles and protection against degradation by DNase. Environmental Science \& Technology, 40: 2971-2976.

22 Camacho TJH, Rubiano SY, Hurtado SM. 2014. Near infrared (NIR) diffuse reflectance spectroscopy for the prediction of carbon and nitrogen in an oxisol. Agronomia colombiana, 32: 86-94.

23 Carrero B, Casermeiro M, Gonzalez S. 2010. Evaluación mediante resonancia magnética de la porosidad del suelo tras la aplicación de lodos depuradora. Spanish Journal of Rural Devolopment, 1: 83-89.

24 Carrero B, De La Cruz MT, Casermeiro MA. 2012. Application of Magnetic Resonance Techniques to evaluate soil compaction after grazing. Journal of Soil Science and Plant Nutrition, 12: 165-182.
25 Castilla C, Gutiérrez A, Ramírez L. 2010. Taller Latinoamericano Globalsoilmap.net Atlas de Suelos LAC. Red de Cultivos Permanentes. Rio de Janeiro. EMBRAPA. 26p.

26 Chabrillat S, Ben-Dor E, Viscarra RAR, Dematté JA. 2013. Quantitative soil spectroscopy. Applied and Environmental Soil Science. Vol 2013 article ID 616578, 3 pages.

27 Clemente J, Gregorich E, Simpson R, Courtier D, Simpson M. 2012. Comparison of nuclearmagnetic resonance methods for the analysis of organic matter composition from soil density and particle fractions. Environmental Chemistry, 9: 97-107.

28 Conte P, Piccolo A. 2007. Espectroscopía de resonancia magnética nuclear de estado sólido: una herramienta para caracterizar materia orgánica natural y muestras del suelo. Principios básicos. Óptica Pura y Aplicada, 40: 215-226.

29 Ćorluka V, Hederić Ź, Hadźiselimović M. 2011. Moisture measurement in solid samples using Raman Spectroscopy. Przeglad Elektrotechniczny (Electrical Review), 87: 25-28.

30 Cunha TJF, Novotny EH, Madari BE, Martin-Neto L, Rezende MOO, Canelas LP, Benites VM. 2009. Spectroscopy Characterization of Humic Acids Isolated from Amazonian Dark Earth Soils (Terra Preta De Índio. En:Woods Wl; Teixeira WG; Lehman J; Steiner C, Winklerprins A; Rebellato L. (Ed.). Amazonian dark earths: wim sombroek's vision. Berlin: Springer, Cap 20 . p. 363-372. Embrapa

31 Das R, Ali Md, Hamid SB. 2014. Current applications of X-ray powder diffraction-A review. Reviews on Advanced Materials Science, 38: 95-109. 
32 Davis R, Mauer LJ. 2010. Fourier transform infrared (FT-IR) spectroscopy: A rapid tool for detection nd analysis of foodborne pathogenic bacteria. Current research, Technology and education Topics in Applied Microbiology and microbial Biotechnology. A. Mendez-Vilas (Ed.) Formatex 1582-1594.

33 Derrick MR, Stulik D, Landry JM. 1999. Infrared spectroscopy in conservation science. The Getty conservation Institute, Los Angeles, $236 \mathrm{p}$.

34 Deslattes RD. 2000. High resolution $\mathrm{y}$ - ray spectroscopy: the first 85 years. Journal of Research Institute of Standards and Technology. 105: 1-9.

35 Dick DP, Leite SB, Dalmolin RSD, Almeida HC, Knicker H. 2011. Pinus afforestation in south Brazilian highlands: soil chemical attributes and organic matter composition. Scientia Agricola (Piracicaba, Brazil), 68: 175-181.

36 Dickson DPE, Berry FJ. 1986. Mössbauer spectroscopy. Cambridge University Press. Trowbrigde, Wiltshire. 270p.

37 Drees JC, Wu HBA. 2010. Analytical techniques. p. 130-165. En: Bishop, M. L., Fody, E. P. Schoeff, L.E (Eds.). Clinical chemistry: techniques, principles, correlations. 6th ed. Lybrary of Congresss Cataloging in Publications Data. Baltimore, 705 p.

38 Drewsen M. 2002. Notes on laser Hazard. 16p.

39 Enev V, Pospíšilová L', Klučáková M, Liptaj T, Doskočil L. 2014. Spectral Characterization of Selected Humic Substances. Soil \& Water Research, 9: 9-17.

40 Fan TW, Lane EN, Chekmenev E, Wittebort RJ, Higashi RM. 2004. Synthesis and physico chemical properties in soil humic substances. The Journal of Peptide Research 63: 253-264.
41 Fasurová N, Pospíšilová L. 2010. Characterization of soil humic substances by ultraviolet-visible and synchronous fluorescence spectroscopy. Journal of Central European Agricultura, 11: 351-358.

42 Feyziyev F, Babayev M, Priori S, L’Abate G. 2016. Using visible-near infrared spectroscopy to predict soil properties of mugan plain, Azerbaijan. Open Journal of Soil Science. 6: 52-58.

43 Fierãscu RC, Dimitriu I, Munteanu V. 2007. Monitoring of soils charged with heavy metals. Analele Universitãtii din Bucureşti-Chime Anul XVI (serie noua). I, 87-92.

44 Fonte SJ, Nesper M, Hegglin D, Velásquez JE, Ramírez B, Rao IM, Bernasconi SM, Bunemann EK, Frossard E, Oberson A. 2014. Pasture degradation impacts soil phosphorus storage via changes to aggregate-associated soil organic matter in highly weathered tropical soils. Soil Biology\& Biochemistry, 68: 150-157.

45 García J, Ballesteros M. 2005. Evaluación de parámetros de calidad para la determinación de carbono orgánico en suelos. Revista Colombiana de Química, 34: 201-209.

46 Gillespie AW, Walley FL, Farrell RE, Leinweber P, Regier T, Blyth RIR. 2007. N and C K-edge XANES spectroscopy of Rhizosphere and non-Rhizosphere soils. Earth and Environmental science. Canadian Ligth Source. Activity Report, 76-77p

47 Griffiths J. 2008. A brief history of mass spectrometry. Analytical chemistry, 80: 5678-5683.

48 Haney RL Jin VL, Johnson MW, Haney EB, Harmel RD, Arnold JG, White MJ. 2015. Analysis methods for the determination of anthropogenic additions of $\mathrm{P}$ to agricultural soils. Open Journal of Soil Science, 5: 59-68. 
49 Haque MD. E, Nairuzzaman M, Imam MH. 2013. X-ray diffraction studies of some Madhupur clay samples of savar and Dhaka of Bangladesh with special emphasis on clay minerals. International Journal of Scientifica \& Technology Research, 2: 174-180.

50 Hassouna M, Théraulaz F, Massiani C. 2012. Production and elimination of water extractable organic matter in a calcareous soil as assessed by UVNis absorption and fluorescence spectroscopy of its fractions isolated on XAD-8/4 resins. Geoderma, 189-190: 404-414.

51 HeZ, Ohno T, Wu F, Olk DC, Honeycutt CW, Olanya M. 2008. Capillary Electrophoresis and Fluorescence Excitation-Emission Matrix Spectroscopy for Characterization of Humic Substances. Soil Science Society of America Journal, 72: 1248-1255.

52 Huang C, Liu S, Li R, Sun F, Zhou Y, Yu G. 2016. Spectroscopic evidence of the improvement of reactive iron mineral content in red soil by long term application of swine manure. Public Library of Science ONE. Doi: 10.1371/Journal. pone.0146364. $15 \mathrm{p}$.

53 Huang Q, Zhu J, Qjao X, Cai P, Rong X, Liang W, Cheng W. 2009. Conformation, activity and proteolytic stability of acid phosphatase on clay minerals and soil colloids from an alfisol. Colloids Surf. B Biointerfaces, 74: 279-283.

54 Jaramillo D. 2004. El recurso suelo y la competitividad del sector agrario colombiano. Competitividad del sector agrario colombiano: posibilidades y limitaciones. Medellín. Universidad Nacional. 26p.

55 Jenkins R. 2000. X ray techniques : overview. 13269-13288. En: Encyclopedia of Analytical
Chemistry, Meyers RA (Ed.) Jhon Wiley \& Sons Ltd. Chichester.

56 Jimenez A, Ravelo D, Gomez J. 2010. sistemas de adquisición, almacenamiento y análisis de información fenológica para el manejo de plagas y enfermedades de un duraznero mediante tecnologías de agricultura de precisión. Revista Tecnura, 14: 41-51.

57 Junk MJN. 2012. Electron Paramagnetic resonance theory. Chapter 2. 7-52p. En: assesing the functional structure of molecular transporter by EPR spectroscopy. Springer-Verlag. Theses. Berlin. 212p.

58 Kovacs H, Moskau D, Spraul M. 2005. Cryogenically cooled probes-a leap in NMR technology. Progress in Nuclear Magnetic Resonance Spectroscopy, 46, 131-155.

59 Kulkarni Y, Warhade KK, Bahekar S. 2014. Primary nutrients determination in the soil using UV spectroscopy. International Journal of Emerging Engineering Research and Tecnology, 2: 198-204.

60 Kuś S, Marczenko Z, Obarski. N. 1996. Derivative UV VIS spectrophotometry in analytical chemistry. Chemia analityczna. (Warsaw) 41, 899-927.

61 Lasia A. 1999.Electrochemical impedance spectroscopy and its applications. 1-53p. En: Application, modern aspect of electrochemistry. Conway BE, Bockris J, White RE (ed.). kluver academic/ plenum publishers, New York, 32, 143-248.

62 Lewicka SD, Dyckmans J, Kaiser J, Marca A, Augustin J, Well R. 2016. Biogeosciences, 13: 1129-1144.

63 Li X, Wang X, Zhao Q, Zhang Y, Zhou Q. 2016. In situ representation of soil/sediment conductivity 
using electrochemical impedance spectroscopy, Sensor 16: 1-9.

64 Linker R. 2008. Soil Classification via mid-infrared spectroscopy. En IFIP International Federation for information Processing, Vol 259; Computer and Computing Technologies in Agriculture. Vol. 2; Daoliang Li; (Boston; Springer), pp. 1137-1146.

65 Linker R. 2012. Application of FTIR Spectroscopy to Agricultural Soils Analysis. Capitulo 8. En: Fourier Transforms - New Analytical Approaches and FTIR Strategies. Faculty of Civil and Environmental Engineering Technion - Israel Institute of Technology Israel. 21p.

66 Lizarazo SIA, Alfonso COA. 2011. Aplicaciones de la agricultura de precisión en palma de aceite "Elaeis guineensis" e hibrido Ox G. Revista de Ingeniería. Universidad de los Andes. Ene-Jun. 124-130.

67 Lokhande VN. Deshmukh RR. 2016. Monitoring arsenic contamination in agriculture soil using spectroradiometer. International Journal of Innovative Research in Sciences, Engineering and Technology, 5: 5508-5513.

68 López S, Mejía J, Pareja J, Molina A. 2011. Efecto de la humedad, el tamaño de partícula y la forma de preparación de la muestra sobre la señal de Mg I en espectroscopía de plasma generados por láser (LIBS) en muestras de suelos. Puente Revista Científica. Universidad Pontifica Bolivariana, 5:15-20.

69 Lu P, Wang L, Zheng N, Linghao L, Wenhao Z. 2013. Prediction of soil properties using laboratory VIS-NIR spectroscopy and Hyperion imagery. Journal of Geochemical Exploration, 132: 26-33.
70 Luiza A, Meire J, Roberto C, Albertino J. 2012. Isotope determination of sulfur by mass spectrometry in soil samples. Revista Brasileira de Ciěncia do Solo, 36:1787-1793.

71 Luna AS, Lima ICA, Rocha WFC, Araujo JR, Kuznetsov A, Ferreira EHM, Boqué R, Ferré J. 2014. Classification of soil samples based on Raman spectroscopy and $X$ ray fluorescence spectrometry combined with chemometrics methods and variable selection. Analytical Methods, 6: 8930-8939.

72 Mahajan GR, Sahoo RN, Pandey RN, Gupta VK, Kumar D. 2014. Using Hyperspectral remote sensing techniques to monitor nitrogen, phosphorus, sulphur and potassium in wheat (Triticum aestivum L.) Precision Agriculture, 15: 499-522.

73 Makarov MI, Haumaier L, Zech W, Marfenina OE, Lysak LV. 2005. Can 31P RMN spectroscopy be used to indicate the origins of soil organic phosphates?. Soil Biology \& Biochemistry, 37: 15-25.

74 Martínez HE, Fuentes EJ, Acevedo HE. 2008. Carbono orgánico y propiedades del suelo. Revista de la Ciencia del Suelo y Nutrición Vegetal, 8: 68-96.

75 Marzaioli F, Lubritto C, Delgaldo I, Donofrio Á, Cotrufo F. 2009. Comparison of different soil organic matter fractionation methodologies: evidences from ultrasensitive $14 \mathrm{C}$ measurements. Nuclear Instruments and Methods in Physics Research B, 268: 1062-1066.

76 Melo VF, Schaefer CEGR, Uchoa SCP, Simoes ML, Neto LM, Junior JFV. 2011. Electron paramagnetic resonance and thermogravimetric characterization of humic acids in nutrient-rich 
soils from the raposa Serra do sol indian reserve, Roraima, Brazil. Interciencia, 36: 450-455.

77 Morugán CA, Arcenegui V, García OF, Mataix SJ, Mataix BJ. 2013. Application of soil quality indices to asses the status of agricultural soils irrigated treated wastewaters. Solid Earth, 4: 119-127

78 Mosquera CS, Martínez MJ, Guerrero JA, Hansen EW. 2010. Caracterización estructural de la matería orgánica de tres suelos provenientes del municipio de Aquitania-Boyacá, Colombia. Revista Colombiana de Química, 39: 47-60.

79 Neetu K, Ankit G, Ruchi T, Ajay B, Prashant B. 2012. A review on mass spectrometry detectors. International Research Journal of Pharmacy. 3(10) 33-42

80 Nevidomskaya D, Minkina T, Soldatov A, Motuzova G, Podkovyrina Y. 2014. Usage of $X$ ray absorption spectroscopy and extractive fractionation in studies of the Cu (II) and Zn (II) ions in soils. Eurasian Journal of Soil Science, 3: 238-244.

81 Nocita M, Stevens A, Wesemael B, Van, Aitkenhead $M$, Bachmann $M$, Barthès $B$, Dor $E$, Brown D.J, Clairotte M, Csorba A, Dardenne P, Demattê JA. M, Genot V, Guerrero C, Knadel M, Montanarella L, Noon C, Ramirez L.L, Robertson J, Sakai H, Soriano-Disla JM, Shepherd KD, Stenberg B, Towett EK, Vargas R, Wetterlind J. 2015. Chapter Four-Soil spectroscopy: An alternative to wet chemistry for soil monitoring. Advances in Agronomy, 132: 139-159.

82 Nogueira OR, Ignácio AC, Salvio MA. 2009. The use of total luminiscence spectroscopy in the investigation of the effects of different rice mangement prectices on humic substances of a planosol. Revista Brasileira de Ciencia do Solo, 33: 1147-1152.

83 Ogundalu AO, Oyekan GL. 2014. Mineralogical and geotechnical characterization of maidaguri black cotton soil by X-ray diffraction (XRD), x-ray photoelectron (XPS) and scanning electron spectroscopy (SEM). International Journal of Engineering and Technology, 4: 345-353.

84 Oliveros BA, Macias FA, Marin D, Molinillo JMG, Barbosa LCA, Demuner AJ. 2012. Cinética y mecanismo de la degradación en suelo de la 2-hidroxi-(2H)-1,4-benzoxazin-3(4H)-ona, un aleloquímico fitotóxico de las gramíneas. Avances en Ciencias e Ingeniería, 3: 47-67.

85 Pareja J, López S, Jaramillo D, Hahn DW, Molina A. 2013. Laser ablation-laser induced breakdown spectroscopy for the measurement of total elemental concentration in soils. Applied Optics, 52: 2470-2477.

86 Parikh SJ, Goyne KW, Margenot AJ, Mukome FND, Calderon FJ. 2014. Soil chemical insights provided through vibrational spectroscopy. Publication from USDA-ARS/UNI. Faculty. Paper 1471.

87 Patterson G, Day R, Piston D. 2001. Fluorescent protein spectra. Journal of Cell Science, 114: 837-838.

88 Pohlmeier A, Vergeldt F, Gerkema E. 2010. MRI in Soils: Determination of Water Content Changes Due to Root Water Uptake by Means of a MultiSlice-Multi-Echo Sequence (MSME). The Open Magnetic Resonance Journal, 3: 69-74.

89 Purmalis O, Klavins M. 2013. Comparative study of peat humic acids by using uv spectroscopy. 1st 
Annual International Interdisciplinary Conference AllC, 24-26 April, Azores, Portugal - Proceedings. 857-866p.

90 Qui J, Darilek J, Huang B, Zhao Y, Sun W, Gu Z. 2009. Evaluating soil quality indices in an agricultural region of Jiangsu Province, China. Geoderma, 149: 325-334.

91 Ramadan, BN. 2011. Sample preparation for flame atomic absorption spectroscopy: an overview. RASĀYAN Journal of Chemistry, 4: 49-55.

92 Rewald B, Meinem C. 2013. Plant roots and spectroscopic methods-analysing species, biomass and vitality. Frontiers in Plant Science, 4: 1-9.

93 Roach N, Reddy KR. 2004. Review of X-ray, electron beam and spectroscopy methods for characterization of contaminated soils. Trends in Soil Science 3, 1-18.

94 Saikia BJ, Parthasarathy, G. 2010. Fourier transform infrared spectroscopic characterization of kaolinite from Assam and Meghalaya, Northeastern India. Journal of Modern Physics 1, 206-210.

95 Saito B, Seckler MM. 2014. Alkaline extraction of humic substances from peat applied to organicmineral fertilizer production. Brazilian Journal of Chemical Engineering, 31: 675-682.

96 Santos JV, Mangrich AS, Pereira BF, Pillon CN, Novotny EH, Bonagamba TJ, Abb-Braun G, Frimmel FH. 2013. 13C NMR and EPR spectroscopic evaluation of oil shale mined soil recuperation. Joufrnal of the Brazilian Chemical Society, 24: 320-326.

97 Sauer M, Hofkens J, Enderlein J. 2011. Handbook of fluorescence spectroscopy and imaging. Wiley-VCH Verlag GmbH \& Co, KGaA, Weinheim. 282p.
98 Schmid T, Rodriguez RM, Escribano P, Palacios OA, Ben DE, Plaza A, Milewski R, Huesca M, Bracken A, Cicuéndez V, Pelayo M, Chabrillat S. 2016. Characterization of soil erosion indicators using hyperspectral data from a mediterranean rainfed cultivated region. IEEE Journal of Selected topics in Applied Earth Observations and Remote Sensing, 9: 845-860.

99 Schwartz G, Eshel G, Ben-Dor E. (2011). Reflectance Spectroscopy as a Tool for Monitoring Contaminated Soils, Soil Contamination, MSc Simone Pascucci (Ed.), ISBN: 978-953-307-647-8, InTech, 180p.

100 Segal E, Shouse P.J, Bradford S.A, Skaggs TH, Corwin DL. 2009. Measuring particle size distribution using laser diffraction: implications for predicting soil hydraulic properties. Soil Science, 174 (12): 639-645p.

101 Shepherd KD. 2010. Soil spectral diagnosticsinfrared, x-ray and laser diffraction spectroscopy for rapid soil characterization in the Africa soil information service. 19th World congress of soil science, soil solutions for a changing world. Brisbane, Australia, 24-27.

102 Shiferaw A, Hergarten C. 2014. Visible near infrared (VisNIR) spectrocopy for predicting organic carbon in Ethiopia. Journal of Ecology and the Natural Environment, 6: 126-139.

103 Sparks DL. 2006. Advances in elucidating biogeochemical processes in soils: it's about scale and interfaces. Journal of Geochemical Exploration, 88: 243-245.

104 Štěpánek P, Bouř P. 2011. Application of magnetic circular dichroism for studies or organic 
molecules. WDS'11 Proceeding of contributed papers, Part III, 177-181.

105 Tadini AM, Pantano G, Toffoli AL, Fontaine B, Spaccini R, Piccolo A, Moreira AB, Bisinoti MC. 2015. Off-line TMAH-GC/MS characterization of humic substances extracted from river sediments of borthwestern Sao Paulo under different soil uses. Science of the Total Environment, 506-507: 234-240.

106 Tian Y, Zhang J, Weixing C, Yan Z. 2013. Laboratory assessment of three quantitative methods for estimating the organic matter content of soils in China based on visible/near-infrared reflectance spectra. Geoderma, 202-203: 161- 170.

107 Towet EK, Shepherd KD, Cadisch G. 2013. Quantification of total element concentrations in soils using total $X$ ray fluorescence spectroscopy (TXRF). Science of the Total Environment, 463464: 374-388.

108 Trujillo Q, Mejia SME, Bravo CJA, Ceron LML, Rufasto E. 2011. Avances en la caracterización mineralógica de los suelos del rio Chancay, Lambayeque, por difractometria de rayos $X$ y espectroscopia Mössbauer. Revista de Investigación de Física, 14: 1-5.

109 Udenfriend S. 1995. Development of the spectrophotofluorometer and its commercialization. Protein Science, 4: 542-551.

110 Urbano MFA. 2013. Redes de sensores inalambricos aplicadas a optimizacion en agricultura de precision para cultivos de cafe en colombia. Journal de Ciencia e Ingeniería, 5: 46-52.

111 Wang J, He T, Lv CH, Chen Y, Jian W. 2010. Mapping soil organic matter based on land degradation spectral response units using
Hyperion images. International Journal of Applied Earth Observation and Geoinformation, 12S: S171-S180.

112 Wasson A, Bischof L, Zwart A, Watt M. 2016. A portable fluorescence spectroscopy imaging system for automated root phenotyping in soil cores in the field. Journal of Experimental Botany. doi: 10.1093/jxb/erv570. 11p.

113 Willis JB. 1993. The Birth of the atomic absorption spectrometer and its early applications in clinical chemistry. Clinical Chemistry, 39: 155-160.

114 Willman C. 2006. Applications of gamma ray spectroscopy of spent nuclear fuel for safeguards and encapsulation. Dissertation. Faculty of science and technology. Uppsala university. Uppsala. Sweden. $79 \mathrm{p}$.

115 Yong W, Peng G, Liang Z. 2010. A Spectral Index for Estimating Soil Salinity in the Yellow River Delta Region of China Using EO-1 Hyperion Data. Pedosphere, 20: 378-388.

116 Yücesoy C. 2000. Determination of some parameters which affect the accuracy and precision in UV VIS spectrophotometry. Journal of Faculty of Pharmacy of Ankara, 29: 7-18.

117 Zamudio A, Carrascal C, Pulido J, Gallardo E, Ávila M, Vargas A, Vera D. 2006. Métodos analíticos de laboratorio de Suelos. $6^{a}$ ed. Instituto Geográfico Agustín Codazzi (IGAC). Bogotá. D.C. $648 p$ 